\title{
Huhungan antara Kadar High Density lipoproteindengan Derajat Sepsis Berdasarkan Skor Pediatric Logistic Organ Dysfunction
}

\author{
Emi Yulianti, Antonius H. Pudjiadi, Mardjanis Said, E.M. Dady Suyoko, \\ Hindra Irawan Satari, Pramita Gayatri \\ Departemen Ilmu Kesehatan Anak Fakultas Kedokteran Universitas Indonesia/Rumah Sakit Cipto \\ Mangunkusumo, Jakarta
}

\begin{abstract}
Latar belakang. Sepsis masih merupakan penyebab kematian terbesar di Pediatric Intensive Care Unit (PICU). Peran high density lipoprotein (HDL) pada keadaan sepsis mengikat dan menetralisir lipopolisakarida (LPS), menghambat adhesi molekul dalam kaskade inflamasi, dan sebagai antioksidan.

Tujuan. Mengetahui profil HDL pada anak sepsis serta mengetahui hubungan kadar HDL dengan derajat sepsis berdasarkan skor pediatric logistic organ dysfunction (PELOD).

Metode. Studi potong lintang pada anak sepsis di PICU Rumah Sakit Cipto Mangunkusumo (RSCM) usia 1 bulan- 18 tahun antara April-Agustus 2011.

Hasil. Didapatkan 34 subjek, dengan sebaran terbanyak pada kelompok usia <2 tahun (19/34). Terdapat hubungan antara kematian dengan skor PELOD $>20(p=0,000)$. Lima dari 7 pasien dengan skor PELOD $>20$ ditemukan mempunyai kadar HDL rendah $(\mathrm{p}=1)$. Tidak didapatkan hubungan yang bermakna antara kematian dengan kadar HDL ( $\mathrm{p}=\mathbf{0 , 2 4 8 )}$. Terdapat korelasi lemah berbanding terbalik antara kadar HDL dengan skoring PELOD tetapi tidak bermakna secara statistik $(r=-0,304, p=0,080)$

Kesimpulan. Pasien sepsis dengan skor PELOD tinggi cenderung memiliki kadar HDL rendah.

Sari Pediatri 2013;15(2):116-21.
\end{abstract}

Kata kunci: sepsis, anak, HDL, skor PELOD

epsis merupakan penyebab kematian terbesar di Pediatric Intensive Care Unit (PICU). American College of Chest Physicians/Society of Critical Care Medicine melaporkan bahwa kejadian

Alamat korespondensi:

Dr. Emi Yulianti, SpA. Departemen Ilmu Kesehatan Anak Fakultas Kedokteran Universitas Indonesia/Rumah Sakit Cipto Mangunkusumo. Jl Salemba No 71, Jakarta sepsis berat mencapai 56\% dari 1000 anak sakit berat di Amerika Serikat pada tahun 2005 dengan angka kematian 10,3\%. Systemic Inflamatory Response Syndrome (SIRS) dan sepsis merupakan penyebab kematian pada $82 \%$ dari pasien yang dirawat di PICU..$^{1-3}$ Pada tahun 2009, terdapat 502 pasien anak yang dirawat di PICU Departemen Ilmu Kesehatan Anak Rumah Sakit Cipto Mangunkusumo (RSCM), dan 19,3\% di antaranya mengalami sepsis dengan mortalitas sebesar $54 \%$. 
Toksin yang berperan pada sindrom sepsis, antara lain lipopolisakarida (LPS) yang merupakan dinding membran terluar atau endotoksin bakteri Gram negative, dan lipoteichoic acid (LTA) yang merupakan dinding membran terluar atau eksotoksin bakteri Gram positif. Ikatan LPS/LTA pada reseptor membran sel pejamu akan mengaktifkan kaskade inflamasi yang memicu lepasnya mediator inflamasi dan akan menimbulkan manifestasi klinis sepsis. Endotoksin merupakan penyebab tersering sepsis yang akan kami bahas lebih lanjut. ${ }^{4}$

High density lipoprotein (HDL) adalah bentuk lipoporotein berdensitas tinggi yang terbukti berperan dalam mengikat dan menetralisir LPS, menghambat adhesi molekul dalam kaskade inflamasi, dan sebagai antioksidan. Pemberian rekombinan HDL (rHDL), very low density lipoprotein (VLDL), atau kilomikron dan emulsi lipid, terbukti menghambat masuknya LPS kedalam sitoplasma., ${ }^{5}$ Studi yang meneliti hubungan antara perubahan kadar kolesterol plasma sebagai indikator infeksi dengan beratnya infeksi masih terbatas jumlahnya, sehingga masih perlu dilakukan penelitian lebih lanjut.

Berbagai sistem skoring untuk menilai derajat disfungsi organ pada populasi pediatrik dengan kondisi kritis terus dikembangkan seperti skor PRISM (Pediatric Risk of Mortality), PEMOD (Pediatric Multiple Organ Dysfunction) dan PELOD (Pediatric Logistic Organ Dysfunction) yang merupakan pengembangan sistem skoring PEMOD. Sistem skoring tersebut bertujuan untuk menggambarkan dan menilai kuantitas derajat beratnya penyakit secara akurat berdasarkan perubahan disfungsi organ secara klinis serta untuk memprediksi mortalitas pada pasien yang dirawat di PICU. Sistem skoring PELOD dipilih karena sistem ini dapat digunakan untuk menilai prognosis pasien dari waktu ke waktu dan telah divalidasi diberbagai multisenter. ${ }^{7}$

Penelitian mengenai penurunan kadar HDL dengan beratnya derajat penyakit yang dinilai dengan berbagai sistem skoring tersebut masih terbatas khususnya pada populasi pediatrik. Hingga saat ini, sepanjang pengetahuan penulis, belum ada data mengenai kadar HDL pada anak sepsis di Indonesia. Penelitian ini merupakan penelitian pendahuluan yang diharapkan dapat menjadi data dasar untuk studi lanjutan yang lebih besar dan sebagai masukan untuk tata laksana sepsis yang lebih baik khususnya mengenai manfaat pemberian HDL pada anak sepsis sehingga dapat menurunkan morbiditas dan mortalitas akibat sepsis.

\section{Metode}

Penelitian studi potong lintang yang dilakukan di PICU RSCM Jakarta pada semua anak sepsis usia 1 bulan sampai dengan 18 tahun pada April-Agustus 2011. Populasi target adalah semua anak dengan sepsis di Indonesia dengan populasi terjangkau adalah semua anak dengan sepsis di PICU RSCM yang dinilai dengan skor PELOD. Kriteria inklusi adalah pasien yang didiagnosis sepsis berdasarkan international pediatric sepsis consensus conference yang dirawat di PICU RSCM dan dieksklusi apabila menderita kelainan metabolisme, gizi lebih atau gizi buruk, mendapatkan terapi lipid atau insulin, dan apabila orang tua pasien tidak bersedia ikut dalam penelitian. Estimasi jumlah subjek adalah 32 pasien dihitung berdasarkan rumus besar sampel untuk mencari korelasi.

Penelitian diawali dengan mendeteksi seluruh pasien sepsis bakterialis yang dirawat di PICU. Data dasar pasien diambil pertama kali masuk perawatan, kemudian dilakukan pemeriksaan laboratorium untuk data skor PELOD dan HDL. Data diolah menggunakan program SPSS 17. Interpretasi hasil berupa proporsi dan korelasi. Data disajikan dalam bentuk tekstular dan tabular.

Batasan operasional pada penelitian ini

- Sepsis adalah sindrom inflamasi sistemik (SIRS) yang terjadi akibat infeksi, baik infeksi yang sudah terbukti maupun yang masih dicurigai. Sindrom inflamasi sistemik ditegakkan apabila didapatkan minimal 2 dari 4 kriteria berikut (salah satunya harus berupa suhu atau hitung leukosit abnormal $)^{8}$

- $\quad$ Suhu tubuh $>38,5^{\circ} \mathrm{C}$ atau $<36^{\circ} \mathrm{C}$.

- Takikardia, didefinisikan sebagai laju denyut jantung $>2$ SD untuk usia tanpa adanya stimulus eksternal atau pengaruh obat. Pada anak $\leq 1$ tahun dapat terjadi bradikardi.

- Laju napas >2 SD untuk usia atau pasien membutuhkan ventilasi mekanik yang bukan disebabkan oleh kelainan neuromuskular atau pengaruh obat anestesia.

- Hitung leukosit meningkat atau menurun untuk usia (bukan sebagai akibat leukopenia yang diinduksi oleh kemoterapi) atau neutrofil imatur $>10 \%$.

- Bukti infeksi bakteri pada adalah temuan kultur positif (darah, urin, atau spesimen lainnya) dan/ atau kadar prokalsitonin $\geq 0,5 \mathrm{ng} / \mathrm{ml} .^{9}$ 
- Kadar HDL diperiksa menggunakan sampel darah beku minimal $2 \mathrm{ml}$, kemudian diproses untuk diambil serumnya sebanyak $10 \mu \mathrm{l}$. Kadar HDL normal $>55 \mathrm{mg} / \mathrm{dL}$ untuk laki-laki dan $>65 \mathrm{mg} /$ dL untuk perempuan. Kadar HDL yang dianggap rendah adalah $<20 \mathrm{mg} / \mathrm{dL} .{ }^{10}$

- Skor PELOD dinilai dengan menggunakan sistem komputerisasi dengan cara memasukkan semua data untuk melihat probabilitas kematian dengan menggunakan metode regresi logistik. Hasil pengolahan data berupa skor yang selanjutnya dikonversikan menjadi persentase perkiraan angka kematian

- Status gizi dinilai berdasarkan pemeriksaan klinis serta pemeriksaan antropometris berat badan (BB) dan tinggi badan (TB) yang diplot pada kurva CDC-NCHS 2000.

\section{Hasil}

Sejumlah 45 pasien sepsis yang disebabkan oleh infeksi bakteri, 4 pasien dengan gizi buruk, 5 meninggal sebelum data HDL diambil, 1 dengan atresia bilier, dan 1 dengan sindrom nefrotik. Sebagai hasil akhir, diperoleh 34 subjek penelitian yang memenuhi kriteria penelitian. Tabel 1 menunjukkan sebaran karakteristik subjek penelitian. Subjek laki-laki didapatkan lebih banyak dibandingkan perempuan dengan rasio sebesar 3,3:1. Sembilan pasien dari total 34 subjek meninggal dunia, di antaranya 6 pasien dengan skor PELOD $>20$ (6/9). Terdapat hubungan yang bermakna antara skor PELOD $>20$ dengan kematian, dengan nilai $\mathrm{p}=0,000$ (Tabel 2).

Lima dari 7 pasien dengan skor PELOD tinggi mempunyai kadar HDL rendah. Tidak didapatkan hubungan bermakna antara kadar HDL dan skor PELOD ( $\mathrm{p}=1)$. (Tabel 3).

Di antara 9 pasien yang meninggal dunia 5 memiliki kadar HDL rendah, sedangkan 19 dari 25 (19/25) pasien yang hidup mempunyai kadar HDL rendah $(\mathrm{p}=0,395)$ (Tabel 4).

Data kadar HDL dan skoring PELOD memiliki distribusi yang tidak normal sehingga uji korelasi antara kedua variabel tersebut dilakukan dengan menggunakan uji korelasi Spearman. Didapatkan korelasi lemah berbanding terbalik antara kadar HDL dengan skoring PELOD $(r=-0,304)$, tetapi tidak bermakna secara statistik dengan $\mathrm{p}=0,080$ (Gambar 1$)$.
Tabel. 1. Karakteristik subjek penelitian $(\mathrm{n}=34)$

\begin{tabular}{|c|c|}
\hline Variabel & $\begin{array}{l}\text { Frekuensi } \\
\text { (Proporsi) }\end{array}$ \\
\hline \multicolumn{2}{|l|}{ Jenis kelamin } \\
\hline Laki-laki & $26(26 / 34)$ \\
\hline Perempuan & $8(8 / 34)$ \\
\hline \multicolumn{2}{|l|}{ Usia (tahun) } \\
\hline Bayi dan anak ( 1 bulan $-<2$ tahun ) & $19(19 / 34)$ \\
\hline Usia pra sekolah ( $2-5$ tahun $)$ & $6(6 / 34)$ \\
\hline Anak usia sekolah ( > 5-12 tahun ) & $5(5 / 34)$ \\
\hline $\begin{array}{l}\text { Remaja dan dewasa muda ( >12 sampai } \\
<18 \text { tahun ) }\end{array}$ & $4(4 / 34)$ \\
\hline Status gizi & $16(16 / 34)$ \\
\hline Baik & $18(18 / 34)$ \\
\hline \multicolumn{2}{|l|}{ Kurang } \\
\hline Diagnosis/fokus infeksi & $5(5 / 34)$ \\
\hline Pneumonia & $8(8 / 34)$ \\
\hline Infeksi susunan saraf pusat & $3(3 / 34)$ \\
\hline Diare & $1(1 / 34)$ \\
\hline Salphingitis & $4(4 / 34)$ \\
\hline Infeksi saluran kemih & $1(1 / 34)$ \\
\hline Miokarditis & $4(4 / 34)$ \\
\hline Sepsis dengan penyebab lain & $8(6 / 34)$ \\
\hline \multicolumn{2}{|l|}{ Pasca operasi } \\
\hline Syok septik & $18(18 / 34)$ \\
\hline Ya & $16(16 / 34)$ \\
\hline \multicolumn{2}{|l|}{ Tidak } \\
\hline Penggunakan vasoaktif & $18(18 / 34)$ \\
\hline Ya & $16(16 / 34)$ \\
\hline \multicolumn{2}{|l|}{ Tidak } \\
\hline Penggunaan ventilasi mekanik & $15(15 / 34)$ \\
\hline Ya & $19(19 / 34)$ \\
\hline \multicolumn{2}{|l|}{ Tidak } \\
\hline Prokalsitonin (ng/mL) & $3(3 / 34)$ \\
\hline$\geq 0,5-\leq 2$ & $9(9 / 34)$ \\
\hline$>2-<10$ & $22(22 / 34)$ \\
\hline \multicolumn{2}{|l|}{$\geq 10$} \\
\hline Luaran & $25(25 / 34)$ \\
\hline Sembuh & $9(9 / 34)$ \\
\hline \multicolumn{2}{|l|}{ Meninggal } \\
\hline Skor PELOD & $7(7 / 34)$ \\
\hline Tinggi ( $\geq 20)$ & $27(27 / 34)$ \\
\hline \multicolumn{2}{|l|}{ Rendah $(<20)$} \\
\hline $\mathrm{HDL}(\mathrm{mg} / \mathrm{dL})$ & $10(10 / 34)$ \\
\hline Tinggi (>20) & $24(24 / 34)$ \\
\hline \multicolumn{2}{|l|}{ Rendah $(\leq 20)$} \\
\hline Kultur (darah, LCS, urin) & $5(5 / 11)$ \\
\hline Steril & $5(5 / 11)$ \\
\hline Tumbuh bakteri & $1(1 / 11)$ \\
\hline Tumbuh jamur & \\
\hline
\end{tabular}


Emi Yulianti dkk: Hubungan antara kadar HDL dengan derajat sepsis berdasarkan skor PELOD

Tabel 2. Hubungan antara skor PELOD dan luaran

\begin{tabular}{lccc}
\hline Skor PELOD & \multicolumn{2}{c}{ Luaran } & Total \\
\cline { 2 - 4 } & Meninggal & Hidup & \\
\hline Tinggi $(\geq 20)$ & 6 & 1 & 7 \\
Rendah $(<20)$ & 3 & 24 & 27 \\
\hline Total & 9 & 25 & 34 \\
\hline
\end{tabular}

Fisher exact test $x^{2}=0,000 ; \mathrm{df}=1 ; \mathrm{p}=0,000$

Tabel 3. Hubungan antara kadar HDL dan skor PELOD

\begin{tabular}{|c|c|c|c|}
\hline \multirow[t]{2}{*}{ HDL (mg/dL) } & \multicolumn{2}{|c|}{ PELOD } & \multirow[t]{2}{*}{ Total } \\
\hline & $\geq 20$ & $<20$ & \\
\hline Tinggi (> 20) & 2 & 8 & 10 \\
\hline Rendah $(\leq 20)$ & 5 & 19 & 24 \\
\hline Total & 7 & 27 & 34 \\
\hline
\end{tabular}

Fisher exact test $x^{2}=0,956 ; \mathrm{df}=1 ; \mathrm{p}=1,000$

Tabel 4. Hubungan antara kadar HDL dan luaran

\begin{tabular}{cccc}
\hline HDL $(\mathrm{mg} / \mathrm{dL})$ & \multicolumn{2}{c}{ Luaran } & Total \\
\cline { 2 - 3 } & Meninggal & Hidup & 10 \\
\hline Tinggi $(>20)$ & 4 & 6 & 24 \\
\hline Rendah $(\leq 20)$ & 5 & 19 & 34 \\
\hline Total & 9 & 25 & \\
\hline
\end{tabular}

Fisher exact test $x^{2}=0,248 ; \mathrm{df}=1 ; \mathrm{p}=0,395$

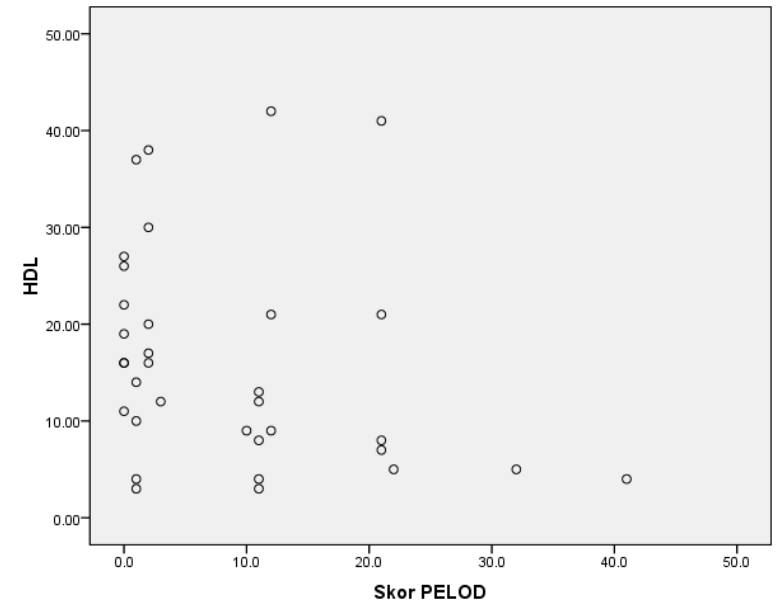

Gambar1. Korelasi antara kadar HDL dengan skor PELOD

\section{Pembahasan}

Penelitian kami mendapatkan rentang usia pasien berkisar antara 1 bulan sampai dengan 16 tahun, sejalan dengan beberapa penelitian terdahulu. ${ }^{11}$ Sebaran usia tertinggi pasien sepsis pada penelitian kami adalah kelompok usia 1 bulan -2 tahun. Luaran yang dicari adalah hidup dan mati, didapatkan 25 (25/34) pasien sembuh, dan 9 (9/34) pasien meninggal. Tujuh pasien dengan skor PELOD $>20$ terdapat 6 pasien yang meninggal $(\mathrm{p}=000)$. Hasil penelitian kami sesuai dengan penelitian Metta $\mathrm{dkk}^{12}$ yang menyatakan bahwa skor PELOD > 20 berkorelasi dengan 50\% risiko kematian dengan sensitivitas dan spesifisitas 54\% dan $80,9 \%$.

Pada penelitian kami, 5 dari 9 pasien yang meninggal memiliki kadar HDL rendah $(<20 \mathrm{mg} /$ $\mathrm{dL}$ ). Temuan tersebut sesuai dengan penelitian Chien dkk, ${ }^{10}$ yaitu 16 dari 30 pasien yang meninggal memiliki kadar HDL rendah $(<20 \mathrm{mg} / \mathrm{dL})$. Namun, hubungan antara kadar HDL dengan skor PELOD yang menunjukkan beratnya derajat penyakit tidak bermakna. Pengambilan data skor PELOD hanya dilakukan satu kali, yaitu saat pasien masuk perawatan PICU. Terdapat kemungkinan bahwa kondisi pasien telah distabilkan dan mendapatkan tatalaksana sebelumnya. Apabila penilaian skor PELOD dilakukan secara berkala, maka skor PELOD tertinggi dapat diambil sehingga derajat sepsis yang sebenarnya dapat lebih tergambarkan.

Sampai saat ini belum ditemukan publikasi penelitian serupa yang mencari hubungan antara 
kadar HDL dengan derajat sepsis yang dinilai menggunakan skor PELOD. Sebuah penelitian prognostik yang menggunakan instrumen lain, yaitu skor acute physiology and chronic health evaluation II (APACHE II), dilakukan oleh Chien $\mathrm{dkk}^{10}$ terhadap 63 pasien sepsis dewasa. Dengan analisis multivariat, studi tersebut mendapatkan kesimpulan bahwa kadar $\mathrm{HDL}<20 \mathrm{mg} / \mathrm{dL}$ pada hari pertama (OR 12,92; IK95\%:2,73-61,29) dan skor APACHE II (OR 1,15; IK95\%:1,04-1,26) merupakan faktor prognostik terjadinya kematian dalam 30 hari perawatan. Namun, penelitian tersebut tidak mencari hubungan langsung antara kadar HDL dan skor APACHE II. Peneliti juga melaporkan bahwa kadar HDL $<15$ mg/dL dapat digunakan sebagai salah satu faktor prognostik beratnya sepsis dengan sensitivitas $75 \%$ dan spesifisitas $83 \%$, kadar $\mathrm{HDL}<20 \mathrm{mg} / \mathrm{dL}$ dengan sensitivitas $92 \%$ dan spesifisitas $80 \%$, sedangkan kadar $\mathrm{HDL}<25 \mathrm{mg} /$ dL mempunyai sensitivitas $100 \%$ dan spesifisitas $57 \%$. Penelitian kami juga menjadi dasar pemilihan cut-off point kadar HDL yang digunakan pada penelitian ini ( $<20 \mathrm{mg} / \mathrm{dL})$ karena angka tersebut menunjukkan sensitivitas dan spesifisitas terbaik.

Kami menemukan bahwa semakin rendah kadar HDL maka skor PELOD semakin tinggi, tetapi secara statistik tidak bermakna $(r=-0,304, p=0,080)$. Jika dilihat dari proporsi subjek penelitian, terlihat kecenderungan kadar HDL rendah, yaitu 5 dari 7 subjek dengan skor PELOD tinggi. Tidak didapatkannya kemaknaan secara statistik pada hubungan dan korelasi antara kadar HDL dan skor PELOD pada penelitian kami mungkin disebabkan oleh jumlah sampel yang kurang memadai.

Vermont $\mathrm{dkk}^{13}$ meneliti korelasi antara derajat keparahan sepsis berat yang disebabkan oleh meningokokus dengan kadar kolesterol total, kadar HDL, dan LDL. Berbeda dengan penelitian kami, sistem skoring yang digunakan oleh Vermont $\mathrm{dkk}^{13}$ adalah pediatric risk of mortality (PRISM) dan sepsis-related organ failure assessment (SOFA). Studi tersebut mendapatkan korelasi berbanding terbalik antara kadar HDL dan skor PRISM serta SOFA, yaitu $-0,47$ dan $-0,34(\mathrm{p}<0,01$ dan $\mathrm{p}<0,05)$. Hasil penelitian kami memiliki koefisien korelasi yang tidak jauh berbeda dengan penelitian tersebut, tetapi secara statistik tidak bermakna. Hal tersebut mungkin disebabkan karena sistem skoring yang dipakai dan saat pengambilan data skoring yang berbeda. Vermont $\mathrm{dkk}^{13}$ melakukan penilaian skoring dan pemeriksaan laboratorium secara berkala, yaitu pada jam ke-6, 12, 24, 48, 72, hari ke-7, dan 1-3 bulan setelah perawatan, sedangkan penelitian kami hanya melakukan penilaian skoring dan pemeriksaan laboratorium pada satu waktu, yaitu pada saat pasien pertama kali masuk perawatan di PICU. Leteurtre $\mathrm{dkk}^{7}$ juga menyarankan untuk menilai skor PELOD secara berkala dari waktu ke waktu dan dinilai dalam waktu satu minggu agar didapat hasil yang akurat untuk menilai besarnya mortalitas,

Penelitian Vermont $\mathrm{dkk}^{13}$ juga menunjukkan bahwa kadar HDL pasien sepsis berat dengan meningokokus baru kembali normal dalam waktu 1-3 bulan pasca perawatan. Dengan demikian, peningkatan HDL terjadi lebih lambat dibandingkan dengan skor PELOD yang dapat berubah dengan cepat mengikuti kondisi klinis pasien. Teori tersebut mungkin dapat menjelaskan skor PELOD yang rendah pada 19 sampel yang memiliki kadar HDL rendah, sehingga memengaruhi hasil uji korelasi yang menjadi tidak bermakna secara statistik. Spesimen darah untuk pemeriksaan HDL pada penelitian kami, umumnya diambil saat pasien pertama kali masuk ke PICU RSCM dalam kondisi yang telah relatif lebih stabil dengan skor PELOD rendah karena telah mendapatkan perawatan dan tatalaksana definitif di IGD selama beberapa hari sebelumnya.

\section{Kesimpulan}

Pada lebih dari separuh anak dengan sepsis berat yang memiliki skor PELOD > 20, didapatkan kadar HDL rendah $(<20 \mathrm{mg} / \mathrm{dL})$. Pasien sepsis dengan kadar HDL rendah cenderung memiliki skor PELOD tinggi, tetapi hubungan ini tidak bermakna secara statistik $(\mathrm{r}=-0,304 ; \mathrm{p}=0,080)$. Perlu dilakukan penelitian lebih lanjut dengan pememeriksaan kadar HDL dan skoring PELOD secara berkala pada pasien sepsis dengan jumlah subjek yang lebih besar.

\section{Daftar pustaka}

1. Vosylius S, Sipylaite J, Ivaskesvicius S. Sequential organ failure assessment score as the determinant of outcome for patient with severe sepsis. Croatian Med J 2004;45:715-20.

2. Leclere F, Leteurtre S, Duhamel A, Grandbastien B, Proulx F, Martinot A, dkk. Cumulative influence of organ 
dysfunction and septic state on mortality of critically ill children. Am J Resp Crit Care Med 2005;171:348-53.

3. Proulx F, Fayon M, Farrel C, Lacroix J, Gauthier M. Epidemiology of sepsis and multiple organ dysfunction syndrome in children. Chest 1996;109:1033-7.

4. Almog Y, Shefer A, Novack V, Maimon N, Barski L, Eizinger M, dkk. Prior stantin therapy is associated with a decreased rate of severe sepsis. Circulation 2004;110:880-5.

5. Cocklerill G, McDonald M, Filipe H, Cuzzocrea S, Miller N, Thiermermann C. High density lipoprotein reduce organ injury and organ dysfunction in a rat model of hemorrhagic shock. FESEB J 2001;15:1941-52.

6. Levels J, Lemaire L, Ende Avd, SJ SvD, Lanschot Jv. Lipid composition and lipopolysaccharide binding capacity of lipoprotein in plasma and lymph of patient with systemic inflammatory response syndrome and multiple organ failure. Crit Care Med 2003;31:1647-53.

7. Leteurtre S, Martinot A, Duhamel A, Gauvin F, Grandbastien B, Nam T, dkk. Development of pediatric multiple organ dysfunction score: use two strategies. Med Decis Making 1999;19:399-410.
8. Goldstein B, Giroir B, Randolp A. International pediatric sepsis consensus conference: definition for sepsis and organ dysfunction in pediatric. Pediatr Crit Care Med 2005;6:1-8.

9. Meisner M. Biomarkers of sepsis: clinically useful? Current Opinion in Critical Care 2005;11:473-80.

10. Chien J, Jerng J, Yu C, Yang P. Low serum level of highdensity lipoprotein cholesterol is a poor prognostic factor for severe sepsis. Crit Care Med 2005;33:1688-93.

11. Liuba P, Persson J, Luoma J, Yla H, Pesonen E. Acute infection in children are accompanied by oxidative modification of LDL and decrease of HDL cholesterol, and are followed by thickening of carotid intima-media. Euro Heart J 2003;24:515-21.

12. Metta D, Soebardja D, Hudaya D. The use of pediatric logistic organ dysfunction (PELOD) scoring system to determine the procnosis of patients in pediatric intensive care units. Pediatrica Indonesiana 2006;46:1-6.

13. Vermont C, Brinker M, Kakeci N, Kleijn Ed, Rijke Yd, Joosten K, dkk. Serum lipid and disease severity in children with severe meningococcal sepsis. Crit Care Med 2005;33:1610-15. 